Volume 15 - Número 2 - ago/dez de 2020

\title{
O QUE ESTÁ ESCRITO AQUI? REDESCOBRINDO A GRAMÁTICA NOS CAMINHOS PARA A LEITURA
}

\author{
WHAT'S WRITTEN HERE? REDESCOVERING GRAMMAR ON THE PATHS \\ TO READING
}

\author{
Daniela Cid de Garcia ${ }^{1}$ \\ Marília Uchôa Cavalcanti Lott de Moraes Costa ${ }^{2}$ \\ Cristiane Oliveira da Silva ${ }^{3}$ \\ Rogério Santana Lourenço ${ }^{4}$
}

\begin{abstract}
RESUMO: As práticas de leitura na escola têm recebido relevantes contribuições da Linguística Textual no Brasil. A ausência das vertentes formais nessa conversa, no entanto, produziu uma lacuna nessa construção de conhecimento, sobretudo no que diz respeito às implicações cognitivas da interação entre unidades gramaticais e demandas de processamento. $\mathrm{O}$ artigo reflete sobre algumas contribuições relevantes de trabalhos recentes da Teoria Gramatical e da Psicolinguística (MAIA, 2018; MAIA, 2019; OLIVEIRA; QUAREZEMIN, 2016) acerca da relação entre conhecimento sintático e desempenho escolar. Considerando os limites de atenção e memória durante o processamento, apresentamos a hipótese de que a consciência sintática pode ter impacto nas estratégias implementadas durante a leitura, levando o foco atencional para os termos centrais da unidade linguística processada. Esse pode ser um recurso importante para lidar com estruturas com grande complexidade estrutural, que não são comuns na fala vernacular mas que estão presentes em muitos gêneros textuais. Trazemos, ainda, uma reflexão sobre a relação entre aquisição da linguagem e desempenho em leitura. Em seguida, discutimos de que forma(s) esses conhecimentos podem ser apropriados na tentativa de se pensarem propostas pedagógicas.
\end{abstract}

PALAVRAS-CHAVE: psicolinguística, consciência sintática, processamento de leitura, estratégias de leitura, consciência leitora

\begin{abstract}
Reading practices at school have received relevant contributions from textual linguistics in Brazil. The absence of formal approaches in this conversation, however, produced a gap in the knowledge construction, especially with regard to the cognitive implications of the interaction between grammatical units and processing demands. This article reflects on some relevant contributions from Grammatical Theory and Psycholinguistics (MAIA, 2018; MAIA, 2019; OLIVEIRA; QUAREZEMIN, 2016) about the relation between syntactic knowledge and school performance. Considering attention and memory constraints during processing, we present the hypothesis that syntactic awareness may impact strategies implemented during reading, taking the attentional focus to key elements of the linguistic unit being processed. This resource may be important to deal with structures with high structural complexity, which are not common in the vernacular varieties of language, but are common in many written genres. Then, we discuss in what ways these types of knowledge may be used in an attempt to think about pedagogical proposals.
\end{abstract}

KEYWORDS: psycholinguistics, syntax, reading processing, sentence processing, reading strategies

\section{Introdução}

Não existe disputa com relação ao fato de que a leitura é uma atividade complexa, que demanda diferentes conhecimentos e habilidades. Como não se trata de um objeto simples e, portanto,

\footnotetext{
${ }^{1}$ Departamento de Letras Anglo-Germânicas, Faculdade de Letras, Universidade Federal do Rio de Janeiro

2 Departamento de Letras-Libras, Faculdade de Letras, Universidade Federal do Rio de Janeiro

${ }^{3}$ School of Humanities, Massey University, Nova Zelândia

${ }^{4}$ Laboratório de Estudos do Discurso Imagem e Som- Museu Nacional/ Universidade Federal do Rio de Janeiro.
} 
fácil de isolar, é necessário um trabalho colaborativo e um olhar por vários ângulos para se ter uma descrição mais completa e unificada. Neste artigo, discutiremos um desses vários ângulos a partir dos quais construímos um conhecimento sobre o processo de ler e compreender um texto escrito: o impacto do conhecimento gramatical na leitura. Nossa discussão se configura em três níveis. Por um lado, estabelecemos alguns aspectos relevantes sobre o papel da sintaxe na leitura, considerando as restrições de processamento que se aplicam a essa modalidade específica. Além disso, trazemos uma reflexão sobre a relação entre aquisição da linguagem e desempenho em leitura. Em seguida, discutimos de que forma(s) esse conhecimento pode ser apropriado na tentativa de se pensarem propostas pedagógicas. Entendemos que pensar meios de ensinar a ler depende também de saber o que leitores hábeis fazem quando lêem e como essa habilidade é desenvolvida.

As práticas de leitura na escola ganharam novos ares com o desenvolvimento da linguística textual no Brasil. O olhar sobre o texto ressignificou-se e a prática de leitura passou a ser tratada, mais do que como um processo de decodificação, como um lugar de interação entre sujeitos sociais (KOCH; ELIAS, 2007). Essa perspectiva sobre a leitura auxilia a repensar as noções de sujeito e texto em que convergem ações linguísticas, cognitivas e sociais (BEAUGRANDE, 1997). No entanto, a ausência dos estudos formais sobre a linguagem na discussão sobre a leitura gerou uma lacuna no que diz respeito a essa tentativa de entender o objeto leitura de forma mais completa. Nos últimos anos tem havido uma mobilização por parte de pesquisadores que atuam nas áreas da Teoria Gramatical e da Psicolinguística em fomentar um contato maior entre esses campos da ciência da linguagem e as ciências da educação brasileira (cf. MAIA, 2018, 2019; PILATI, 2017; KENEDY, 2013; 2016). Esses estudos têm em comum a proposta de renovar o olhar para o ensino de gramática na escola.

Pilati $(2019$; 2017) traz uma contribuição original ao chamar a atenção para o caráter fragmentado com que a concepção de língua chega às salas de aula. A autora aponta ainda a imprecisão com que o sistema linguístico tem sido abordado nos documentos oficiais, em que não há menção às "dimensões relacionadas a aspectos biológicos e psicológicos da língua" (PILATI, 2019; p. 349) e que têm relevância, segundo a autora, tanto para a compreensão do objeto de estudo quanto por promoverem "autonomia e autoestima linguística" (p.350). Levando em conta o inatismo e a estrutura gerativa da linguagem, Pilati (2017) propõe oficinas e atividades com o objetivo de promover reflexão crítica do estudante sobre sua própria língua, a partir da qual poderá expandir para uma "apropriação progressiva da língua padrão" (PILATI, 2017; p. 17). Nesse sentido, em vez de as aulas de gramática serem um espaço para memorização de listas e regras, elas passam a ser um espaço para que o estudante ativamente se aproprie da língua como um sistema simples e gerativo, por meio da manipulação agentiva e consciente das categorias linguísticas e de suas possibilidades combinatórias.

Maia (2018b) propõe que a análise sintática e o estudo gramatical sejam realizados em conjunto com uma reflexão sobre os dados empíricos e o processamento mental da linguagem. $\mathrm{O}$ autor critica o ensino tradicional por este estar afastado da dimensão cognitiva na qual, naturalmente, a capacidade linguística se insere. Assim, Maia investiga o rastreamento ocular da leitura em períodos compostos a partir de oficinas realizadas com estudantes do ensino básico. Com base nos resultados obtidos, Maia caracteriza dois perfis de leitores: leitores estruturantes e leitores lineares. Leitores lineares seriam aqueles que teriam maior dificuldade em estruturar sentenças complexas. Tal dificuldade leva a um desengajamento do leitor linear, sobretudo quando a ordem canônica dos sintagmas ou das orações é subvertida. Isso mostra que os leitores estruturantes adquiriram ferramentas cognitivas para lidar com a modalidade escrita, mesmo que essas ferramentas não tenham sido explicitadas por meio de ensino formal. Maia propõe, então, trazer à consciência os mecanismos cognitivos necessários para lidar com a variante escrita, o que ele chama de "consciência leitora", que poderia auxiliar leitores lineares em seu processo de letramento. 
Volume 15 - Número 2 - ago/dez de 2020

Kenedy (2013) propõe um ensino de gramática com uma nomenclatura gramatical minimalista e focado na noção de sintagma. O autor aponta para uma perspectiva gramatical descritiva em detrimento das extensas nomenclaturas geralmente trabalhadas nas aulas de língua do ensino básico no Brasil. Kenedy destaca que a gramática descritiva pode ser um instrumento de reflexão sobre a língua e descreve que o ensino de noções gramaticais, tais como sujeito, predicado, morfema etc. não deve ser o objeto da aprendizagem, mas, sim, uma ferramenta de acesso e apropriação da norma padrão brasileira. A partir de análises gramaticais baseadas na teoria gerativa X-barra, o autor propõe uma nomenclatura mínima para o estudo sintático na educação básica, que inclui apenas: sujeito, predicado, complemento e adjunto. $\mathrm{O}$ autor se apoia nas recomendações dos PCNs para manter a análise linguística como uma das atividades das aulas de língua, mas apresenta uma metalinguagem mínima para que essas aulas sejam focadas na reflexão sobre a língua e não em uma extensa lista de rótulos.

Kenedy (2016) argumenta, com base na Hipótese das Múltiplas Gramáticas de Roeper e Amaral (2014), que a cultura letrada exige a aquisição de uma segunda língua, um segundo português, com grandes diferenças lexicais, gramaticais e discursivas daquele adquirido como língua materna pelas crianças. Essa situação se agrava ao se constatar que crianças oriundas de ambientes com cultura letrada, geralmente aquelas em melhor situação socioeconômica, foram expostas a maior input da variedade culta da língua e, portanto, se apropriam de forma mais orgânica (não-explícita) da escrita nas escolas. Por isso, o sistema escolar deveria atentar para essa desigualdade sociolinguística e não pressupor a aquisição da variedade culta como certa e automática e, sim, como o aprendizado de uma nova língua que precisa estar disponível e ser ensinada/aprendida nas escolas. Dessa forma, Kenedy argumenta que ler e escrever não é apenas (de)codificar sua língua materna usando símbolos gráficos do alfabeto, mas sim "uma incursão num mundo linguístico completamente diferente, cujo domínio é uma condição necessária para o pleno acesso à cultura letrada."

O objetivo deste artigo é propor uma articulação entre as ideias trazidas por esses autores e o processamento psicolinguístico da leitura, trazendo para a discussão a dimensão das restrições a que o leitor está submetido durante a performance leitora. Entretemos aqui a hipótese de que o conhecimento sintático pode ter impacto nas estratégias implementadas durante a leitura e que dificuldades no mapeamento da estrutura afetam a compreensão, assim como acontece quando se tem dificuldades no reconhecimento lexical por problemas na decodificação grafofônica. Isso ocorre porque os recursos atencionais e de memória podem se esgotar nesse nível mais baixo, não restando recursos para os processos envolvidos na compreensão em sentido mais amplo.

Sabe-se que adquirir expertise em leitura depende de uma etapa de decifrar o código alfabético. Essa etapa, como afirma Castles et al (2018), é crucial em sistemas de escrita alfabéticos e funciona como fundação para as etapas posteriores. Após essa etapa, que pode ser considerada como um gatilho importante para a leitura, tornar-se um leitor hábil depende também de desenvolver maior fluência na habilidade de reconhecer palavras escritas, o que se desenvolve com a experiência leitora. A hipótese da qualidade lexical estabelece que uma leitura efetiva depende da existência de alta qualidade de representação lexical, com informação ortográfica, fonológica e sintático-semânticas bem especificadas (PERFETTI, 2002). Palavras encontradas com frequência teriam maior qualidade lexical do que palavras menos conhecidas.

Poderíamos dizer que a exposição a estruturas sintáticas mais frequentes na escrita geraria maior qualidade sintática dessas estruturas em relação a estruturas menos conhecidas? Não queremos dizer que o processamento sintático se dá com base em frequência, mas a ideia de que experiência gera qualidade parece encontrar respaldo nos dados. Por outro lado, a percepção da sintaxe como um sistema finito e gerativo parece ser um gatilho com importância similar a decifrar o código alfabético. A partir daí, assim como um maratonista consegue alcançar distâncias mais longas focando em estratégias para reservar energia, o leitor teria maior fluidez na leitura se pudesse focar em identificar 
os elementos centrais em um período, consciente de que, independente do tamanho, ele é composto de elementos pequenos que foram se concatenando, para chegar ao período longo que encontramos - nossa maratona leitora. Atingir níveis satisfatórios de compreensão dependeria da automatização dessas estratégias, e, ainda que alguns leitores hábeis desenvolvam essas ferramentas sem explicitação formal, é possível que uma consciência inicial desses mecanismos seja um passo necessário para alavancar a possibilidade de leituras mais estruturantes e eficientes. Nesse sentido, é importante trazer a sintaxe para as discussões sobre leitura. $O$ foco na decodificação grafofônica e na sociointeração, apenas, não contempla uma parte importante do objeto.

Um programa de pesquisa que busque caracterizar mais detalhadamente o papel do conhecimento $^{5}$ sintático na leitura e do desenvolvimento da "consciência leitora" (MAIA, 2018b) deve levar em consideração, entre outras, as seguintes questões: (1) existe uma relação entre dificuldade em compreender um texto e baixa consciência sintática? (2) leitores hábeis aplicam estratégias de leitura descendentes dentro do período para achar os elementos que compõem a estrutura argumental das orações e não esgotar recursos atencionais e de memória em uma leitura linear? (3) a consciência e expertise em identificar e manipular constituintes da própria língua, em sua variedade vernacular, pode servir de gatilho para manipular períodos mais complexos, presentes em gêneros escritos? (4) a experiência em navegar por períodos longos e complexos gera maior qualidade de representação de estruturas sintáticas? (5) qual seria a natureza dessa representação? (6) Quais seriam os impactos das etapas iniciais de escolarização (creche e educação infantil) em que se promove um ambiente de brincar com a língua via leitura compartilhada e cantigas "recursivas", como "a velha a fiar", por exemplo? Este artigo não se propõe a responder todas as questões, mas a levantar alguns aspectos que consideramos relevantes nessa busca.

A leitura de textos escritos formais ou literários privilegiados no ambiente escolar pode demandar maior carga cognitiva -- i.e. esforço mental na execução de uma tarefa -- do que é demandado em textos escritos informais. Esses textos podem se distinguir das variedades vernaculares da língua (KENEDY, 2016; GEE, 2004), seja por apresentarem estrutura hierárquica mais densa e extensa ou por operarem de forma inovadora com a estrutura da língua. Assim, a prática da leitura no contexto escolar proporciona operar variedades da língua diferentes daquela a que o estudante é exaustivamente exposto durante a aquisição (KATO, 1998; GEE, 2004; HOFF, 2006; KENEDY, 2016). Na seção 3 discutimos como o contato com o mundo letrado oferece uma nova variedade da língua, com itens lexicais e regras gramaticais singulares. Essa nova variedade não é intransponível, mas não deve ser tomada como elemento já assimilado durante as práticas de leitura.

Considerando que a compreensão leitora deve partir do que está, de fato, escrito, deve-se considerar a relevância do conteúdo gramatical quando se pensam práticas de leitura no contexto escolar. Desenvolver a consciência sintática a partir de estruturas presentes nas variedades vernaculares deve ser uma etapa importante para a análise de estruturas presentes em variedades acadêmicas e literárias, pois partiria daquilo que é familiar para o potencial desconhecido. Cabe ressaltar que um trabalho com as estruturas da língua deve evitar cair na prática tradicional de transferência de conhecimento sobre listas de regras e de rótulos (PILATI, 2017; KENEDY, 2013). Acreditamos que, nesse aspecto, o papel da escola seja prover mais oportunidades de processamento e de reflexão analítica de estruturas sintáticas, tendo em vista o desenvolvimento de uma metacognição gramatical. Na seção 4 , discutiremos como esse exercício analítico sobre a estrutura do período fomenta a metacognição gramatical e auxilia no desenvolvimento da capacidade científica.

\footnotetext{
${ }^{5}$ Costa (2017) diferencia conhecimento sintático de consciência sintática, sendo o primeiro o conhecimento tácito que trazemos por sermos falantes de uma língua e o segundo, o controle deliberado dos falantes sobre as unidades sintáticas da língua. Aqui, utilizamos o termo conhecimento sintático de forma mais abrangente, quando não determinamos se há de fato consciência ou não sobre o processo.
} 
Volume 15 - Número 2 - ago/dez de 2020

\section{A sintaxe na leitura}

Uma característica importante das línguas naturais é que elas se estruturam - e são processadas - por meio de unidades gramaticais. Desde a segunda metade do século XX, a psicolinguística tem realizado experimentos que evidenciam a relevância de constituintes sintáticos no processamento da linguagem. Em um estudo clássico, por exemplo, Fodor e Bever (1965) testaram a sensibilidade de sujeitos para a existência de fronteiras sintáticas manipulando a sobreposição de clicks sobre períodos gravados. O lugar do click ocorria em maior ou menor distância em relação às fronteiras sintáticas. Os resultados obtidos revelaram que cliques em região de fronteira sintática foram localizados com maior precisão do que os cliques em posição adjacente e que a percepção dos cliques adjacentes foi deslocada de modo a garantir a integridade das fronteiras sintáticas. Esses achados despontaram como argumentos de que a compreensão das sentenças depende de operações mentais sobre a estrutura sentencial.

Sabe-se que a estrutura sintática se beneficia de outras informações, como pistas prosódicas (STEINHAUER; ALTER; FRIEDERICI, 1999) e estatísticas (SAFFRAN; ASLIN; NEWPORT, 1996), por exemplo. Com o intuito de investigar o papel da estrutura durante a compreensão, Ding et al (2016) manipularam materiais de fala a fim de dissociar a estrutura sintática dessas outras pistas. Ao monitorar a atividade cortical de participantes, observou-se uma codificação neural para cada nível linguístico. Ou seja, ao escutar uma sequência de sílabas aleatórias, que preservava propriedades acústicas, mas eliminava estrutura, capturaram-se circuitos corticais dedicados a processar informação em nível silábico apenas. Por outro lado, encontraram-se circuitos corticais dedicados a processar estruturas abstratas e maiores quando os participantes escutaram sequência de palavras que formavam uma estrutura sintática. Tais resultados evidenciam a existência de operações corticais especializadas para o processamento sintático durante a compreensão da fala. Dessa forma, o reconhecimento e análise da estrutura gramatical não é apenas uma atividade relegada às aulas de sintaxe, mas um recurso da mente humana para o processamento de frases. Considerando a relevância dessas unidades gramaticais para o processamento, deve-se esperar que a extração do sentido de um texto durante a leitura tenha uma etapa que envolva o reconhecimento dessas unidades no material escrito.

Além de reconhecer e integrar constituintes em orações e períodos, compreender um texto depende, também, de lembrar das palavras que formam esses constituintes e de recuperar, selecionar e integrar informações prévias. Assim, atenção e memória de trabalho são essenciais para recuperar e manipular unidades constitutivas durante o processamento de sentenças. Uma característica importante sobre nossos recursos atencionais e de memória de trabalho, no entanto, é o fato de que eles têm capacidade limitada. Ou seja, quanto maior a lista de unidades com que a memória deve operar, maior será a carga cognitiva demandada (MILLER, 1956; THALMANN; SOUZA; OBERAUER, 2019). Nesse sentido, é menos custoso guardar, por exemplo, uma palavra formada por dez letras do que uma sequência de dez letras que não formam uma palavra, ou seja, uma unidade. $\mathrm{O}$ mesmo se aplica para unidades maiores, como orações e períodos. Sabemos que "[...] quanto maior o elemento que tomamos como unidade significativa, maior será a quantidade de material que poderemos processar e manter na memória ao mesmo tempo" (KLEIMAN, 2013, p. 50). Dessa forma, é mais fácil recuperar uma oração de dez palavras do que uma sequência de dez palavras que não forma uma oração (KLEIMAN, 2013; PINKER, 2014). Semelhante ao que ocorre com a memória, nossos recursos atencionais são limitados. Esses recursos dizem respeito à nossa capacidade de estar vigilante e alerta em busca de informações. De forma ótima, esses recursos são utilizados para filtrar e selecionar informações relevantes e dispensar elementos distratores que competem por nossa atenção e podem nos levar para outros caminhos diferentes do nosso objetivo pretendido inicialmente. Em ciência cognitiva, a atenção refere-se aos mecanismos em nosso cérebro que selecionam, 
amplificam, canalizam a informação e aprofundam seu processamento (DEHAENE, 2020). Selecionar a informação relevante é fundamental para o aprendizado; sem isso podemos nos perder em meio a uma enorme quantidade de dados. Sendo assim, um modelo que busque caracterizar o que fazemos quando lemos deve levar em conta a articulação entre nosso conhecimento sintático e esses limites cognitivos do processamento. É comum encontrar, em diversos gêneros textuais, períodos muito longos, em que devemos filtrar, entre diversos elementos intervenientes, os elementos centrais da estrutura argumental das orações.

Muitos modelos já foram propostos em uma tentativa de entender e mapear os processos envolvidos na compreensão leitora (PERFETTI, 1985; STANOVICH, 1980; PERFETTI, 1999; PERFETTI; LANDI; OAKHILL, 2013; RAYNER E POLLATSEK, 1999; KHALIFA; WEIR, 2009; REICHLE, RAYNER \& POLLATSEK, 2003). Esses estudos que têm a leitura como objeto reconhecem que se trata de um processo que envolve a integração de habilidades cognitivas de níveis mais baixos e de níveis mais altos ${ }^{6}$. Tende-se a chamar de processos de nível baixo os recursos envolvidos no reconhecimento visual de palavras, processos grafofônicos, processamentos fonológico e ortográfico. Acima desses viriam o processamento sintático e semântico, o conhecimento pragmático, as inferências e o conhecimento de mundo, de organização textual e intertextual.

Os modelos de leitura estabelecem que o processo da leitura envolve a aplicação de estratégias articulando esses níveis. Perspectivas mais recentes reconhecem que, ao lermos, integramos dois tipos de estratégias: estratégias ascendentes (bottom up; cf. FLESCH, 1955; GOUGH, 1972; LABERGE; SAMUELS, 1974), que envolvem a combinação de unidades menores em unidades maiores a partir do input visual (ou tátil), e estratégias descendentes (top down; cf. SCHANK, 1978; SMITH, 1971), que envolvem o uso de informações prévias, de conhecimento de mundo, que o leitor traz tanto para planejar que tipo de leitura aplicar, (se rápida ou cuidadosa, por exemplo), quanto para antecipar informação e compor o sentido do texto lido. Leitores hábeis se beneficiam dessas duas estratégias.

Tradicionalmente, estratégias de leitura descendentes, como skimming (ler superficialmente de forma global para identificar a ideia geral do texto) e scanning (passar os olhos para recuperar informações em locais específicos), tendem a contemplar pedaços de texto maiores que o período e, mesmo quando há menção em recuperar informação dentro do período (KHALIFA; WEIR, 2009), trata-se de uma informação qualquer que se encontra dentro do escopo dessa unidade linguística. No entanto, não há uma articulação com a sintaxe do período. Aqui, propomos, como uma estratégia importante de scanning, a busca pelos argumentos principais das orações ${ }^{7}$-- uma estratégia que deve ser desenvolvida à medida em que o leitor (1) entende que a língua é um sistema simples e gerativo e (2) se expõe a diferentes estruturas presentes no gêneros escritos. Isso permite uma leitura estruturante, que já foi associada, em um escopo mais macrotextual, a uma melhor recuperação mnemônica do material lido. Ou seja, trata-se de escanear o período em busca de constituintes

\footnotetext{
${ }^{6}$ Nota-se que os elementos que compõem os níveis altos e baixos nos modelos de leitura não seriam os mesmos na Teoria Gramatical. Se pensarmos em uma estrutura arbórea de sentença, os elementos mais baixos são aqueles relacionados à estrutura argumental, enquanto os elementos mais altos teriam relações com o que é denominado periferia esquerda, em que observamos elementos de tópico e foco, além de elementos relacionados com a pragmática e discurso. Percebe-se assim que há um desencontro na granularidade dos elementos trabalhados. Nos últimos 30 anos em teoria sintática, tem sido proposta a ideia de que há sintaxe em todos os níveis: dentro das palavras, nas frases e nos períodos. Por isso, ter uma visão encapsulada da sintaxe como sendo de nível alto e a atrelar a elementos mais macro como discurso e pragmática gera uma perda da capilaridade que a sintaxe tem, acabando por não discutir o elemento do meio entre o acesso lexical e os elementos mais sociais, ao julgar que a sintaxe estaria nesse nível mais alto. Precisamos trazer a sintaxe para o seu lugar de esqueleto e intermediadora desses diferentes níveis para que possamos contemplar o que é uma questão de acesso às palavras, à estrutura e ao conhecimento de mundo.

${ }^{7}$ Por argumento estamos nos referindo aos elementos que compõem a estrutura argumental.
} 
específicos, passando mais rápido por elementos que não são centrais à estrutura argumental para a qual os recursos atencionais estão voltados naquele dado momento. Nota-se que, ainda que essa seja uma estratégia de leitura descendente, ela é guiada pelo conhecimento sintático. Ela parte da consciência de que o período, por maior que seja, é uma unidade que apresenta uma estrutura hierárquica. Uma leitura estruturante, portanto, dedicando maior atenção à busca pela estrutura argumental central, permite que sejamos capazes de compreender períodos maiores, já que não estaríamos lidando com palavras somadas linearmente, mas com unidades maiores (sintagmas, orações) organizadas hierarquicamente. Como vimos acima, uma oração ocupa menos carga de memória do que uma sequência de palavras do mesmo tamanho. A redução dessa carga nos permite lidar com pedaços maiores de texto.

Diversos trabalhos argumentam que estruturar o que se lê libera recursos atencionais e de memória para que seja possível operar uma quantidade maior de informação (MILLER, 1956; KLEIMAN, 2013; HYONA; LORCH; KAAKINEN, 2002; KHALIFA; WEIR, 2009). Essa práxis perpassa os diferentes níveis estruturais inerentes à prática de leitura, a saber: decodificação alfabética, fatiamento sintático e integração textual. Hyona et al. (2002) mostram que leitores que estruturam os diferentes assuntos de um texto em seções apresentam maior capacidade de lembrar o conteúdo. Essa maior capacidade é encontrada em relação a leitores que adotam uma estratégia de leitura linear. Neste artigo, exploramos a relação entre conhecimento sintático e leitura no nível do período.

A seguir, apresentamos alguns resultados de um experimento com rastreamento ocular realizado por bolsistas PIBIC da UFRJ (HENAUT; BASTOS; PATRÍCIO, 2017), que explorou essa relação entre estratégias de leitura e conhecimento sintático. Destacamos aqui os resultados referentes à leitura de um poema, o "Soneto 12" de Shakespeare. Esse texto foi selecionado por apresentar estruturas sintáticas não-canônicas, com elementos intercalados, levando a relações de longa distância. Participaram do experimento 11 estudantes universitários de cursos diversos com idades entre 18 e 35 anos. A tarefa do participante era ler um texto livremente (leitura livre); em seguida ele lia uma pergunta sobre o texto, e então a leitura do mesmo texto era retomada (leitura condicionada). Assim, registraram-se dois padrões de leitura distintos: (i) leitura livre e (ii) leitura condicionada, exemplificados na Figura 1. A pergunta focava em uma informação específica do texto e demandava que o participante aplicasse uma estratégia descendente de leitura (scanning) para encontrar uma informação específica. No exemplo que trazemos, a pergunta era $O$ que acontece quando a hora dobra?. Para responder a essa pergunta o leitor deveria, após "escanear" o poema para encontrar a informação, integrar a oração subordinada Quando a hora dobra em triste e tardo toque, no primeiro verso, com a oração principal sobre tua beleza então questiono, na nona linha do Soneto. Na Figura 1, nota-se o emprego de estratégias diferentes de leitura. Durante a leitura livre, as atividades oculares cobrem uma área maior do texto, indicando uma leitura aparentemente mais cuidadosa, como a leitura default definida por Rayner e Pollatsek (1989). Na leitura condicionada, como se deve esperar de leitores hábeis, o participante identificou a área do texto onde se encontrava a oração subordinada Quando a hora dobra em triste e tardo toque, que coincide com a pergunta $O$ que acontece quando a hora dobra?. Como a oração se encontra no início do texto, não é possível afirmar se o participante aplicou efetivamente uma estratégia descendente de leitura rápida e seletiva para encontrar a informação específica, ou se a identificação foi substancialmente facilitada porque a informação se encontrava no início do texto. Nota-se que a leitura se concentrou na subordinada coincidente com a pergunta, o que indica que uma parte da informação relevante para responder à pergunta foi encontrada. No entanto, nenhum dos 11 participantes teve êxito em responder corretamente à pergunta, mas 5 participantes conseguiram perceber que era necessária a presença de um sintagma verbal: 2 selecionaram um sintagma preposicional presente na pergunta enquanto 4 deram respostas longas tentando responder usando conhecimento de mundo em vez da informação presente no texto. 
Por que, então, mesmo tendo encontrado a informação coincidente com a pergunta, o participante não foi capaz de encontrar a resposta? É possível supor que o fato de os participantes estarem monitorados por um rastreador ocular com apoio de cabeça e queixo, sem acesso a um papel e caneta para auxiliar a destrinchar os constituintes e eliminar possíveis distratores de sua atenção, pode ter contribuído para a dificuldade de encontrar a resposta. O processamento do período exigia manter a vigilância atencional por nove linhas na procura de uma sentença principal para concatenar com Quando a hora dobra e ainda, ao encontrar um candidato, processar a inversão presente em sobre tua beleza questiono, que, em vez de iniciar com um sujeito ou um verbo, inicia com um sintagma preposicional. Isso pode ter se dado por uma dificuldade de isolar, entre todos os elementos intervenientes, a unidade gramatical nuclear relevante para responder à pergunta, nomeadamente o período Quando a hora dobra, sobre tua beleza questiono. Esse isolamento dependeria de não desperdiçar recursos atencionais nos elementos intervenientes, focando apenas em fechar a unidade gramatical.

Trata-se não de saber a terminologia, mas de reconhecer que os sentidos trazidos do mundo se materializam e são codificados na língua por meio de um veículo restrito, a sintaxe, que opera de forma hierárquica e estruturada, apresentando regularidades e padrões. Trata-se também de reiterar que temos muita intuição sobre essas unidades e padrões por sermos falantes de uma língua, qualquer que seja. Pode-se argumentar que o soneto de Shakespeare é um texto difícil, inacessível, já que é um gênero considerado em geral pouco familiar, com quebras na estrutura sintática, nas regras de pontuação e com combinações lexicais pouco frequentes. Por exemplo, lidar com a leitura de hora dobra, uma metáfora não convencionada, gera uma demanda cognitiva a mais para acessar o sentido além do literal. Esses elementos podem dificultar uma identificação imediata e gerar desinteresse do leitor para prosseguir. Uma redução do foco para a gramática pode contribuir para um primeiro contato com o objeto que a princípio parece encapsulado. Ao entender as unidades gramaticais como peças finitas que podem ser manipuladas por regras também finitas para gerar os mais diferentes tipos de combinações, reduz-se o objeto para uma dimensão em que ele se torna mais acessível e manejável. "Quanto mais manejável é o objeto de estudo, mais compreensão sobre ele nós conseguimos obter" (GALLEGO; CHOMSKY, 2020). A estrutura da língua, então, pode ser o elemento comum que permitirá o encontro de mundos muito distantes.

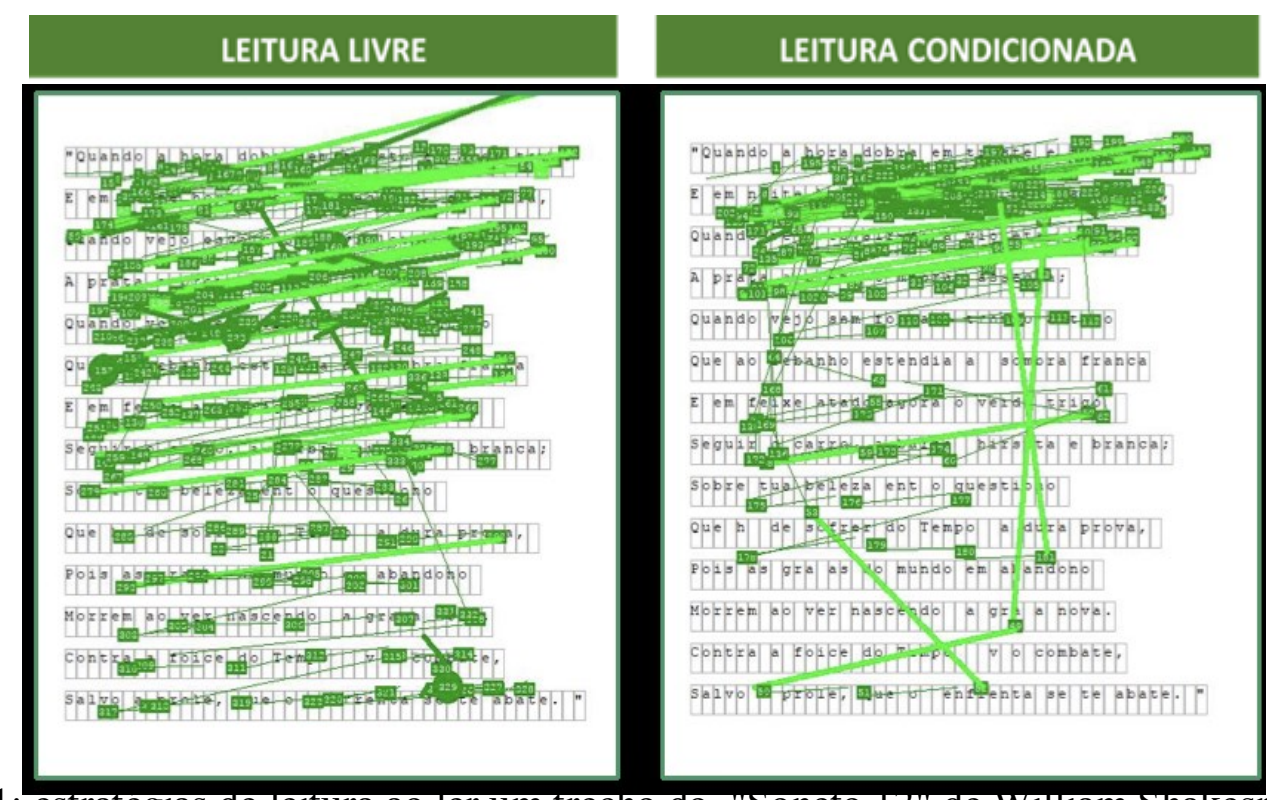

Figura 1: estrategias de leitura ao ler um trecho do "Soneto 12" de William Shakespeare por um estudante universitário 
Volume 15 - Número 2 - ago/dez de 2020

Nota-se, pelas respostas, que os participantes usaram seu conhecimento sintático, possivelmente um conhecimento implícito, para reconhecer a necessidade de uma oração para completar a unidade aberta. No entanto, não encontraram essa oração no texto, o que pode ter sido dificultado pela falta de "consciência leitora". Uma pergunta importante na busca por caracterizar a consciência leitora deve ser se ela envolve o uso da consciência sintática para desenvolver capacidade de percorrer estruturas longas, presentes em diversos gêneros do universo letrado.

Esses resultados suscitam perguntas sobre os mecanismos de leitura que podem encorajar a formulação de hipóteses. O maior desafio dessa empreitada é isolar as diferentes variáveis que insistem em se atravessar durante a leitura. A escolha por textos autênticos mostra-se relevante, pois pode trazer mais variáveis que influenciam a leitura e competem pela atenção e memória do leitor. Por outro lado, a criação de materiais experimentais permite testar hipóteses mais específicas manipulando distância linear e estrutural, entre outros fatores que podem impactar o processamento.

Estudos sobre o processamento de frases podem trazer informações relevantes sobre os recursos cognitivos recrutados e sobre as estratégias implementadas por um leitor para ter sucesso em compreender um texto. A psicolinguística tem uma vasta bibliografia sobre o processamento de sentenças, que reúne o estudo de ambiguidades, da correferência, de sentenças do tipo garden-path e das dependências de longa distância, por exemplo (cf. MAIA; FINGER, 2005; PINKER, 2014). Uma contribuição importante desses estudos é ter lançado luz sobre as demandas cognitivas para o processamento de sentenças, causadas sobretudo pelas restrições na formação de unidades linguísticas e pela dificuldade em manter essas unidades ativas na memória de trabalho. Diversos autores elencam algumas variáveis que contribuem para a complexidade de sentenças que geram dificuldades no processamento (KLEIMAN, 2013; PINKER, 2014; THOMPSON; SHAPIRO, 2007; SCOTT, 2009). Entre essas variáveis, destacam-se a ordem vocabular (mais ou menos canônica), a quantidade de encaixamentos, a distância entre os argumentos da oração e do período, a presença de ambiguidades, a correferenciação intra e intersentencial, e diferenças estruturais entre fala e escrita, ainda que se reconheça que são "objetos que se intersectam em algum lugar" (KLEIMAN, 2013, p. $55)$.

Somam-se a esses estudos, voltados para o processamento linguístico, outros, que têm por objetivo entender como essas variáveis interagem com estratégias aplicadas durante a leitura (KHALIFA; WEIR, 2009). Em um extenso trabalho sobre a psicologia da leitura, Rayner e Pollatsek (1989) se detêm à leitura chamada "default", cuidadosa, não condicionada por fatores externos, como a existência de um fim específico. Khalifa e Weir (2009, p. 46), em consonância com outros autores que se voltam para leitura "não default", argumentam que, "para muitos leitores, a leitura rápida, seletiva e eficiente impõe maiores dificuldades do que a leitura cuidadosa e eficiente". Além da relação entre a leitura e as unidades linguísticas significativas, portanto, uma questão de interesse para a psicolinguística da leitura é que estratégias os leitores implementam em função da complexidade do texto, da familiaridade com o tema, do objetivo da leitura, entre outros aspectos.

A prática de desenvolvimento das capacidades de derivar o significado proposicional a partir da combinação das unidades lexicais constituintes libera recursos atencionais e de memória para que o leitor seja capaz de construir um modelo mental do texto, integrando informação em níveis mais altos, fazendo inferências e monitorando sua compreensão (PERFETTI; LANDI; OAKHILL, 2013; KHALIFA; WEIR, 2009). Ainda que não seja suficiente, percorrer de forma eficiente esses níveis 
mais baixos é necessário porque libera recursos para atingir o que se entende por uma leitura "interacional e crítica", que não se esgota "no que está dito", mas, sim, é construída a partir de um diálogo "gramatical" com esse conteúdo. Sendo assim, tanto uma decodificação eficiente quanto um mapeamento efetivo da estrutura sintática são determinantes para a compreensão em níveis mais altos.

Perfetti, Landi e Oakhill (2013), a partir de uma revisão de trabalhos sobre compreensão leitora em níveis mais altos, concluem que a análise dos níveis mais baixos é necessária, ainda que não suficiente. Para que a compreensão atinja os níveis mais altos, o leitor deve aplicar critérios de monitoramento da coerência do texto. Um ponto importante que o autor destaca é que esse monitoramento da compreensão depende da habilidade do leitor de construir uma representação acurada das sentenças do texto. Ou seja, problemas apresentados por leitores no monitoramento da leitura podem ser caracterizados como uma falha em codificar o significado no nível sentencial (PERFETTI; LANDI; OAKHILL, 2013).

Ainda que, segundo os autores, todos os leitores "relaxem em seus padrões de coerência ocasionalmente" (PERFETTI; LANDI; OAKHILL, 2013 p. 265), o objetivo deve ser adotar padrões rigorosos nesse monitoramento. Esses padrões rigorosos contribuem para que a compreensão do sentido do texto não seja dada a partir de vieses em função da credibilidade do autor ou da fonte, ou pela aceitação de conclusões apenas por identificação com o seu conteúdo, mesmo que elas sejam resultado de argumentações inválidas. Pinker (2014) chama a atenção para o fato de que a sintaxe permite que se comuniquem os elos entre as ideias que queremos transmitir, criando um nexo entre elas.

Nesse sentido, conhecer uma lista extensa de vocabulário de uma língua não deve ser suficiente para produzir criativamente ou para compreender sentenças complexas nessa língua. É possível que, ao lermos um texto, conhecer o significado de palavras isoladas nos permita, a partir do uso de estratégias descendentes de leitura, identificar o conteúdo e até formular hipóteses sobre o argumento presente no texto, levando em consideração quem escreveu, quando, ou em que veículo o texto foi publicado. No entanto, esse tipo de leitura, se aplicada isoladamente, pode levar a uma compreensão imprecisa ou completamente equivocada do material escrito, sobretudo quando o texto traz ideias contraintuitivas. Maia (2006) chama a atenção, por exemplo, para o modo como orações subordinadas podem ser articuladas no período de modo a enfatizar determinados enunciados em favor de outros. Existem evidências de que a ordem em que orações adverbiais se encontram em relação à oração principal tem efeito sobre a compreensão (SMITH; McMAHON, 1970; RIBEIRO, 2017). Uma leitura menos rigorosa pode, portanto, levar ao foco em informações que sobressaem $\mathrm{e}$ menos na argumentação construída. Isso pode produzir efeitos indesejáveis, uma vez que a leitura é uma forma crucial de acesso ao conhecimento nas sociedades letradas.

Dessa forma, ao atentarmos conscientemente para extrair o sentido preciso das orações, estamos nos equipando com recursos importantes para analisar criticamente as informações a que temos acesso por via da leitura. Essa etapa deve ser tão importante quanto reconhecer o texto como uma forma de interação social. Sendo assim, tão importante quanto perguntar quem escreveu, quando ou onde o texto foi publicado, é importante acessar o que está dito de fato no texto. O que está dito no material escrito é finito. As possibilidades de leitura desse material -- e as hipóteses sobre intenções do autor, sobre as entrelinhas -- podem, sim, ser infinitas e dependentes de bagagens individuais, mas essas devem chegar por meio de passos argumentativos a partir do que é extraído quando acessamos o conteúdo semântico básico das sentenças. Para que esse conteúdo seja acessado de maneira eficaz, precisamos conhecer não só o significado das palavras, mas também as formas sintáticas em que elas estão inseridas (PERFETTI; LANDI; OAKHILL, 2013).

Sabemos que muitos problemas que estudantes apresentam em leitura estão de fato relacionados a comprometimentos no acesso lexical, seja pela ausência de itens lexicais em seus repertórios (CHRIST; WANG, 2011), seja pela baixa qualidade lexical desses itens (PERFETTI; 
HART, 2002). Também há autores que argumentam que a compreensão depende sobretudo do conhecimento de mundo que o leitor traz e da sua relação dialógica com o texto, recorrendo a processos de previsão e antecipação. O uso de informação contextual, prévia, de fato contribui para um diálogo efetivo com o material lido. Como reconhece Kleiman (2013, p. 48-49), a leitura pode ser "considerada, do ponto de vista cognitivo, um jogo de adivinhações" (p.49), já que "grande parte do material que lemos é adivinhado ou inferido" (p.48) e não vem diretamente da percepção do que está escrito (GOODMAN, 1967). Por outro lado, existem restrições linguísticas de natureza sintática e semântica que delimitam o que está dito no texto. Quando há dificuldade em acessar de forma precisa esse conteúdo, as estratégias descendentes podem ser desfavoráveis, já que, associadas a uma lassidão na leitura (PERFETTI; LANDI; OAKHILL, 2013), podem levar a equívocos na compreensão. Não se pode negar que certo nível de adivinhação é fundamental para a leitura, dado que prevemos, ao ler, quais são as possíveis estruturas e palavras que podem vir a seguir. Isso é importante para diminuir nosso espaço de hipóteses e reduzir nosso nível atencional naquela atividade. Mas o uso excessivo do recurso de adivinhação ${ }^{8}$ pode levar a estratégias equivocadas quando o texto foge do senso comum e da expectativa default. Em textos mais poéticos, em que o autor joga com a estética e procura caminhos menos trilhados tanto em termos semânticos quanto sintáticos, o leitor pode, apostando todas as suas fichas em uma leitura plausível, não alcançar o texto que está de fato escrito.

Acessar o conteúdo semântico básico das sentenças não deve ser confundido, no entanto, com a soma linear palavra a palavra. E aqui é importante reiterar a especificidade da leitura em relação à língua. O texto está dado, ou seja, não temos acesso a palavra por palavra serialmente, já que o conteúdo é apresentado de forma simultânea. Sendo assim, podemos aplicar estratégias de leitura para percorrer os constituintes de forma hierarquizada, focando a atenção na busca pelos elementos centrais da estrutura argumental em foco. Essa ideia pode parecer contraditória com o argumento de que precisamos ter acesso preciso ao que está escrito, em uma construção ascendente do conteúdo das sentenças. No entanto, para que essa construção seja feita de forma eficiente, é necessário que se foque nos elementos centrais da unidade que está sendo processada.

Nesta seção, ressaltamos o papel das unidades gramaticais e da memória e atenção no processamento de sentenças durante a leitura. Vimos, no experimento, que leitores utilizam seu conhecimento gramatical implícito para saber que uma unidade sintática está aberta e precisa ser fechada e para identificar qual categoria pode ser usada para fechar. No entanto, esse conhecimento não parece ser suficiente para buscar essa informação em determinados textos, que fogem aos padrões linguísticos com que lidamos de forma mais frequente. Na próxima seção, destacamos que certas unidades gramaticais presentes nas variedades de fala e escrita da escola e do universo letrado em geral não coincidem com a variedade vernacular resultante do processo natural de aquisição da linguagem, o que deve ter impacto nos processos de formação da consciência leitora necessária para processar de forma eficiente os períodos em um texto.

\section{Língua do aluno, língua da escola}

Quando se fala em dificuldades em leitura, alguns autores argumentam que, após o estágio de reconhecimento de palavras, não é simples dissociar o que é processamento da leitura e o que é processamento da linguagem (PERFETTI; LANDI; OAKHILL, 2013). Nos primeiros contatos com a leitura, o processamento de leitura e da linguagem são bem distintos, já que adquirir a capacidade de ler envolve decifrar o código escrito, entendendo como a forma dos grafemas e das palavras corresponde a sons e significados da língua (CASTLES et al., 2018; STICHT \& JAMES, 1984; DEHAENE, 2012). A grande dificuldade em leitura estaria, nesse sentido, no estágio inicial de

\footnotetext{
${ }^{8}$ Durante a leitura, somos submetidos a efeitos antecipatórios de natureza lexical, como frequência de palavras e neighborhood density, e de natureza contextual, como cloze probability (cf. PAYNE; FEDERMEIER, 2019)
} 
decodificação. Uma vez que isso foi alcançado, a tarefa do leitor não seria muito diferente daquela do falante de qualquer língua, porque equivaleria a combinar as palavras em unidades maiores, compondo constituintes sintáticos e integrando esses constituintes em orações e períodos, o que aproximaria o processamento da leitura do processamento da linguagem. Talvez por se apostar nessa premissa, o olhar para a estrutura tenha se dissipado nas discussões sobre leitura, que tendem a um movimento pendular entre decodificação, por um lado, e perspectivas mais centradas na relação dialógica entre texto e leitor, por outro.

$\mathrm{Na}$ seção anterior, estabelecemos a importância de se olhar para a estrutura sintática, considerando sua relevância no processamento da linguagem e da leitura. No entanto, é injustificável a visão de que, uma vez decifrado o código alfabético, o estudante não terá problemas em leitura. Como reconhece Perfetti et al (2013), a história não deve terminar na equiparação entre língua e leitura, já que o que lemos tende a ser diferente em conteúdo e estilo do que produzimos e compreendemos nas nossas trocas linguísticas do dia a dia (PERFETTI; LANDI; OAKHILL, 2013). O processo de aquisição de uma língua nos permite acessar diferentes situações em que esta língua é falada e até mesmo acessar a escrita dessa língua uma vez que aprendemos o código alfabético, mas a leitura não é uma transcrição da fala. A leitura funciona com diferentes premissas e especificidades: (i) a leitura é simultânea, temos acesso a todo o texto, diferente da fala, que se externaliza serialmente. Isso afeta o processamento e as estratégias de leitura que podem ser implementadas; (ii) o texto escrito pode apresentar estruturas diferentes daquelas do dia a dia, com maior distância linear entre elementos relacionados, com maior número de encaixes, com períodos, em geral, mais longos, com uma língua orientada para a sintaxe privilegiando estruturas sujeito $>$ predicado.

Alguns autores têm destacado o período como uma "unidade limite entre a língua natural e a escrita" (MAIA, 2019; p. 33), já que ele pode apresentar, na escrita, níveis de complexidade que não estão presentes na fala vernacular (KATO, 1998; KENEDY, 2016). Essa complexidade pode variar em função do gênero textual ou mesmo da distância entre a norma culta contemporânea e as variantes presentes em textos de várias épocas.

Há consenso na literatura de que todas as crianças vão adquirir pelo menos uma língua (CRAIN; LILLO-MARTIN, 1999; LUST, 2006). A aquisição da linguagem seria, nesse sentido, o produto dos processos mentais que tomam como input informação do ambiente e produzem como output a habilidade de produzir e compreender uma língua. Esse processo espontâneo resulta no conjunto de regras e princípios que formam o nosso conhecimento implícito, nossa língua internalizada (CHOMSKY, 1986). O aparato cognitivo inato é fundamental para o desenvolvimento linguístico. Independente de esse aparato ser especificamente linguístico ou não, os modelos de aquisição salientam a importância dos dados como gatilho para o desenvolvimento da linguagem; eles divergem apenas sobre o nível de representação que seria o catalisador do processo de aquisição (PINKER, 1996; GLEITMAN, 1990, MORGAN; DEMUTH, 1996). Nesse sentido, não há modelo de aquisição de linguagem que negue a importância dos dados linguísticos como gatilhos para aquisição. Ou, seja, há consenso para o fato de que o ambiente oferece um suporte contextual universal para a aquisição da linguagem, de modo que todas as crianças adquirem uma língua, pela interação e pelo acesso aos dados, quando estão inseridas em uma comunidade linguística (HOFF, 2006).

Partindo da premissa de que os dados linguísticos são variáveis, é de se esperar que haja variabilidade no processo de aquisição, tanto para um mesmo indivíduo quanto entre indivíduos de uma mesma comunidade de fala. Essa variabilidade não traz impactos insuperáveis em situações do dia a dia em comunicação presencial. No entanto, há certos conhecimentos e práticas que a escola privilegia, e o acesso a esses conhecimentos e práticas varia consideravelmente dependendo do contexto social da criança. Gee (2004) propõe uma distinção entre as variedades linguísticas 
Volume 15 - Número 2 - ago/dez de 2020

vernaculares -- que trazemos como resultado do processo de aquisição -- e variedades especialistas, que são variedades usadas para atividades específicas. Entre essas variedades especialistas, estão variedades associadas ao aprendizado de conteúdos acadêmicos ou a comunicações formais. $\mathrm{O}$ acesso à informação em uma sociedade letrada depende da leitura de textos escritos em variedades não vernaculares, que diferem tanto no vocabulário quanto nas estruturas sintáticas que apresentam.

Kato (1998) argumenta por um isomorfismo parcial entre fala e escrita: "é a escrita que tenta representar a fala -- o que faz de forma parcial -- e, posteriormente, é a fala que procura simular a escrita, o que é obtido também parcialmente."(p. 11) A proposta da autora é a de que haveria uma escrita inicial, que ela chama de escrita 1, que se baseia na fala adquirida "pré-letramento". No processo de se apropriar do código escrito, a criança desenvolve a escrita 2, que, através de convenções rígidas, se descola da fala 1, gerando posteriormente a fala 2 que resultaria do letramento. Dessa forma, a proposta de Kato dialoga com Gee (2004) no sentido de que crianças que entram em contato com ambientes em que essa fala 2 está presente -- seja por hábitos da família ou por entrarem cedo na escola (educação infantil) -- já trariam em sua fala 1 protótipos acadêmicos que alavancariam o desenvolvimento da escrita 2 . Esse processo pode ser iniciado sem que a criança tenha se apropriado do código escrito, mas tendo contato com o mundo letrado em atividades como a leitura compartilhada. Crianças que têm contato com livros na escola e em casa, acabam desenvolvendo estruturas próprias de textos escritos ou mais comuns nesses textos, como, por exemplo, o uso da inversão em "Vamos!: disse o ursinho" (arquivo pessoal - criança de 2 anos 9 meses) ou "Suriléia mãe monstrinha (título do livro) quem escreveu foi [nome inventado] e quem traduziu foi [nome inventado]" (arquivo pessoal - criança de 5 anos e 7 meses). Sendo assim, algumas crianças vão iniciar a etapa de instrução formal em leitura com um repertório maior ou menor desses protótipos, o que vai impactar frontalmente o seu desenvolvimento escolar (ver HOFF, 2006 para uma revisão da literatura). Os impactos podem ser mensuráveis -- como reconhecer práticas sociais que a escola privilegia, como leitura de livros e jornais, ter hipóteses sobre o funcionamento da própria língua e da escrita -- ou mais difíceis de mensurar, como identificação com a comunidade escolar, motivação para atuar naquele espaço social etc.

Nos últimos vinte anos, pesquisadores têm postulado a possibilidade de um bilinguismo universal (ROEPER, 1999), considerando que diferentes modalidades socioculturais da língua possuem regras gramaticais exclusivas e que isso teria um impacto na aquisição da linguagem. Essa hipótese permitiria aos falantes de uma dada língua atribuir a duas gramáticas distintas da mesma língua regras excludentes para um mesmo parâmetro. Tendo em vista a multiplicidade de vivências desde a infância até a vida adulta, seria possível postular a existência de minigramáticas para viabilizar regras computacionais exclusivas e incompatíveis entre si, que seriam fundamentais para compreensão e produção das variadas modalidades da língua (AMARAL; ROEPER, 2014). Esse tipo de situação em que nos deparamos com regras distintas no que é convencionado como uma mesma língua é entendida pelos autores como uma forma de multilinguismo. Kenedy (2016), dialogando com esses autores, propõe que os diferentes gêneros discursivos trazidos pela escola trariam ainda outras minigramáticas, que não coincidiriam com aquelas presentes no repertório das variedades vernaculares.

É possível que parte da diferença entre variedades vernaculares e variedades acadêmicas seja a existência de regras excludentes, configurando mesmo gramáticas distintas. Por exemplo, de acordo com Kenedy (2016), em um levantamento baseado em diferentes fontes, o português vernacular brasileiro culto é uma língua orientada para o discurso, com predomínio de estruturas de tópicocomentário, enquanto a escrita culta seria uma língua orientada para a sintaxe, com predomínio de estruturas sujeito-predicado. É possível também que, mesmo se tratando da mesma gramática, ainda exista uma dificuldade de lidar com as diferentes formas em que as regras e princípios da língua podem se externalizar, considerando os limites de processamento. Por exemplo, para compreender as 
Volume 15 - Número 2 - ago/dez de 2020

estruturas (1) e (2), abaixo, é necessário reconhecer que uma unidade linguística foi aberta e necessita ser fechada. Reconhecer que a relação de subordinação entre as orações nos períodos (1) e (2) é equivalente pode ser um passo para uma leitura mais eficiente de (2). De uma forma ou de outra, um fato é que as variedades vernaculares, em maior ou menor grau, não são suficientes para predizer bons resultados em leitura.

[Quando acordo de manhã cedinho] só penso no café e pão quentinho com manteiga.

\section{[Quando a hora dobra em triste e tardo toque,]} Sobre tua beleza então questiono

Um papel importante da escola, portanto, deve ser desenvolver a consciência sintática para tornar salientes as unidades estruturais do conhecimento intuitivo da língua e, por meio delas, ampliar o repertório das variedades acadêmicas. Essa visão de ampliação em vez de substituição é fundamental, já que considera a língua do aluno como uma variedade vernacular, uma fala 1, a partir da qual o processo de letramento vai se construir. Com isso não há o estigma da punição em relação à língua materna (OLIVEIRA; QUAREZEMIN, 2016), mas a ideia de que se está ampliando o conhecimento linguístico do leitor em formação a partir do trabalho consciente sobre suas minigramáticas e outras que o universo letrado oferece. Segundo Costa et al. (2017), o trabalho da escola tem ainda papel importante com a aquisição de estruturas que se estabilizam mais tardiamente, impactando portanto também o conhecimento implícito de estruturas menos frequentes. $O$ conhecimento explícito é necessário "para atingir níveis elevados em leitura" (COSTA; COSTA; GONÇALVES, 2017, p. 411).

Na seção 2, argumentamos que uma etapa essencial para formação de um leitor, juntamente com ser capaz de "ir além do texto", é acessar o que está dito. Para uma compreensão efetiva -- para dialogar com o texto, concordar com ele, discordar dele -- é necessário que se entenda o que está escrito. Entender depende de dedicar atenção e memória para monitorar constantemente a coerência, o nexo intra e intersentencial. Esse monitoramento depende de acessar de forma eficiente o conteúdo proposicional dos períodos, e o acesso a esse conteúdo pode ser facilitado ou dificultado pela proximidade ou não das estruturas do texto com as estruturas presentes nas variedades vernaculares que os estudantes trazem quando chegam à escola, como discutido na seção 3. Na próxima seção, trazemos uma reflexão sobre como esses conhecimentos podem contribuir para desenvolver a habilidade leitora no ambiente escolar, discutindo como o trabalho com a consciência sintática poderia ajudar estudantes a percorrer visualmente o período de forma mais eficiente.

\section{Conversando com a escola}

O desenvolvimento da linguística no Brasil teve grande impacto nas políticas educacionais de ensino. A sociolinguística e a linguística textual foram áreas que obtiveram êxito em seus empreendimentos de transpor a pesquisa acadêmica para a educação básica. Entretanto, outras áreas da linguística, como a teoria gramatical e a psicolinguística, ficaram por décadas relativamente mais afastadas do ensino de língua portuguesa como língua materna (PILATI, 2017). Nas seções anteriores, destacamos as contribuições dos esforços no sentido de redescobrir a gramática nas práticas de leitura, procurando um caminho diferente dos que deram a ela uma reputação ruim, afastando-a das práticas mais progressistas de ensino.

Esse trabalho não é simples e não pode deixar de observar outras variáveis que atravessam o universo de ensinar e aprender. Como observa Perfetti, Landi e Oakhill (2013), aprender a ler não 
Volume 15 - Número 2 - ago/dez de 2020

depende apenas de adquirir habilidade em leitura, mas depende também de se querer ler. Sendo assim, para que o aprendizado ocorra, há, além das questões de processamento, também o componente volitivo da leitura, que será atingido tanto pela prática, quanto pelo estímulo que cria condições pedagógicas. A disposição dos estudantes em participar de atividades criativas através do contato com textos demonstra que o prazer de ler por vezes está apenas latente, precisando ser despertado. Porém, para que isso aconteça no âmbito da sala de aula, é necessário que a leitura não seja reduzida apenas a obrigatoriedades e avaliações. Além disso, é necessário que as atividades deixem de ser meros exercícios de "copiação" (cf. Marcuschi, 1996) e passem a provocar no estudante a curiosidade para encontrar o texto, percorrê-lo e seguir para além dele.

Gee (2004) propõe uma reflexão sobre situações onde é possível para crianças de diferentes condições socioeconômicas terem em comum êxitos de aprendizado, o que acontece, por exemplo, no caso do interesse por jogos, como Pokemon. Nesse exemplo, trata-se de um jogo composto por cartas com centenas de personagens, organizados em tipologias hierárquicas. Ao jogar Pokemon, as crianças precisam se dedicar a gerar recursos metacognitivos categorizando e hierarquizando as informações a fim de compreendê-las e manipulá-las. Por outro lado, o atual modelo escolar, em sua maioria, falha ao ignorar o desenvolvimento de capacidades inerentes e, portanto, familiares aos estudantes, dificultando o vínculo afetivo com as atividades escolares. Assim, uma grande parcela dos estudantes é afetada, por exemplo, pelo deslocamento entre o seu conhecimento linguístico e aquele que é exigido na escola. A reflexão metacognitiva sobre a estrutura pode ser, portanto, uma porta de entrada para o trânsito entre as estruturas vernaculares adquiridas em casa e as especialistas trabalhadas em aula. A premissa é a de que, independentemente das diferentes origens socioeconômicas, as crianças têm a habilidade de observar o funcionamento de fenômenos, identificar classes naturais, categorizar, formular hipóteses, identificar regras. Se acontece para os jogos, pode acontecer também para a língua.

Partindo dessa premissa, alguns dos trabalhos que têm procurado renovar o olhar para a gramática nas práticas escolares têm apostado na curiosidade e na intuição do aluno sobre a própria língua como uma forma de desencadear o componente volitivo para a leitura (MAIA, 2018; MAIA, 2019; TELLES; LOPES, 2019; ILARI; BASSO, 2017). Esses trabalhos se baseiam em um programa proposto por Honda e O'Neil (1993), que tem como princípio o uso da língua como objeto para desenvolver a capacidade científica. Honda e O'Neil (1993) propõem que a aprendizagem se dê pela descoberta, construindo conhecimento a partir da bagagem que o aprendiz traz e por meio da solução de problemas de forma ativa e colaborativa. Nesse sentido, a língua, sendo um objeto familiar sobre o qual os estudantes teriam bastante intuição, facilitaria o processo de formular hipóteses para explicar seus mecanismos.

Antes de esforços como os de Honda e O'Neil (1993) e Honda et al 2004 vemos esse mesmo caminho nos trabalhos de Paulo Freire, estes para a alfabetização de adultos. A proposta de Freire é "vir do universo vocabular dos grupos populares, expressando a sua real linguagem [...]". Partindo destas perspectivas podemos capitalizar a curiosidade do aluno para entender o mundo que os cerca a partir de um objeto conhecido como sua própria língua. Com isso, teremos cidadãos mais apropriados do seu conhecimento implícito de maneira a serem mais autônomos para manipular esses elementos. Quazeremin e Oliveira (2016) apontam ainda para o ato político significativo de olhar para línguas sem prestígio social. Dado os efeitos sociais de uma visão inferiorizada de ser brasileiro e de sua língua, talvez, advogam as autoras, olhar cientificamente para a própria língua desfaria um trauma coletivo.

A prática descrita acima representa o que Gee (2004) define como um processo cultural. Partindo do conhecimento que o estudante já traz sobre a língua, resultado do seu processo de aquisição, os professores colaboram com os estudantes em um trabalho de levantamento das regularidades de aspectos da língua, sistematizando, categorizando e desenvolvendo teorias 
explicativas. Nesse processo, informações são adicionadas à medida que os estudantes necessitam, de modo que a compreensão é resultado da relevância dessa informação dentro do caminho cognitivo construído na interação. Trazer o exercício de pensar linguisticamente para dentro da sala de aula como parte de um processo no qual o estudante também é agente - tem a possibilidade de tornar a aula de língua algo motivante. Nessa perspectiva, novos conhecimentos são construídos de forma ativa. Assim, esse caminho pode promover muito mais do que novas habilidades de leitura; pode ser o próprio elemento propulsor do desejo de ler.

Trabalhando de forma metacognitiva o conhecimento gramatical, faz-se emergir o conhecimento implícito que temos sobre a nossa própria língua para o nível da consciência. A metacognição, que consiste na monitoração consciente dos processos cognitivos, é reconhecida como um pilar para a aprendizagem (DYPEDAHL, 2018; MAIA; GARCIA; FERNANDES, 2019). Esse automonitoramento sobre um objeto que nos é tão familiar seria determinante para se atingir níveis elevados de compreensão leitora (COSTA; COSTA; GONÇALVES, 2017). Metacognição é um conceito por vezes vago dado sua presença em estudos de diversas disciplinas. Apesar de haver várias acepções do termo, há concordância de que se trata de "uma consciência e reflexão sobre o próprio conhecimento, experiências, emoções e aprendizado" (HAUKAS, 2018 p. 13).

A reflexão metacognitiva sobre estruturas gramaticais pode ser uma poderosa ferramenta para as diferentes frentes do ensino. Os procedimentos gramaticais não se restringem a processos estritamente linguísticos, mas também contribuem para a compreensão de cognições de interface, tais como: classificação, quantificação, consciência para ritmo, teoria de conjuntos, lógica etc. Então, propor uma reflexão consciente sobre a língua natural, além de desenvolver estratégias de leitura e escrita, auxiliaria as ciências em geral e para além delas. Dessa forma, adotar a reflexão sobre o conhecimento gramatical como prática pedagógica pode ser crucial para ampliar o pensamento crítico e científico nas escolas. Com isso, teremos cidadãos apropriados do seu conhecimento implícito e com maior autonomia para manipular estruturas vernaculares articulando-as com aquelas encontradas no ambiente escolar. A reflexão sobre as estruturas linguísticas pode ser transposta para a língua da escola e para a leitura, levando os estudantes a reconhecerem nas variedades acadêmicas estruturas semelhantes às da variedade vernacular.

A análise qualitativa que apresentamos no experimento reportado na seção 2 pode ser um exemplo de como se podem trabalhar práticas de leitura em sala de aula. Ao verem a impressão concreta do movimento dos olhos em um texto lido, os estudantes podem acessar esse processo com curiosidade e distanciamento, formulando hipóteses, explicando seus passos, avaliando o que serviu e o que dificultou, e reformulando seus caminhos pela leitura com informação e protagonismo. Não estamos sugerindo que o trabalho com a leitura precise de aparato tecnológico pouco acessível. $\mathrm{O}$ foco aqui é o trabalho de olhar com curiosidade para os processos -- conscientes ou inconscientes -envolvidos na leitura e sua relação com as unidades gramaticais da língua. Há diversas formas de se fazer isso, desde por uma leitura detalhada parágrafo por parágrafo identificando as unidades gramaticais fundamentais para a compreensão do todo, como encontramos em KOCH e ELIAS (2007) com um enfoque mais semântico, até pela observação de padrões de leitura com metodologia psicolinguística (MAIA, 2018).

A reflexão da própria língua além de desenvolver o pensamento lógico é de extrema importância para a cidadania. Apostando na reflexão sobre uma língua natural para ensinar o método científico que auxilia no ensino de ciências, matemática e desenvolve capacidade de leitura e escrita, fazer científico como uma forma de ampliar o conhecimento sobre gramática. Sendo assim, a reflexão sobre a própria língua, feita pelo aluno, além de desenvolver o pensamento lógico, é de extrema importância para a cidadania. Olhar cientificamente para a própria língua desfaria o pensamento coletivo e inferiorizante de não saber português (QUAREZEMIN; OLIVEIRA, 2016). 
Volume 15 - Número 2 - ago/dez de 2020

\section{Considerações Finais}

A confusão entre o conhecimento das estruturas da língua e o uso dessa língua em diferentes contextos comunicativos tem provocado uma concepção redutora sobre as contribuições dos estudos (psico)sintáticos para as habilidades de leitura. Tal percepção tem como base a crítica de que, nos estudos sintáticos, em especial, há um apagamento das diferenças sociais e dialetais. No entanto, a ausência de algumas áreas da linguística no diálogo sobre as práticas de leitura em sala de aula criou um ponto cego em relação a muitos conhecimentos acumulados pela pesquisa voltada para as etapas mais básicas da compreensão leitora.

Neste artigo, argumentamos que um leitor hábil integra diferentes tipos de conhecimento e de recursos para a compreensão efetiva de um texto. Por ser uma atividade cognitivamente complexa, que exige diferentes demandas simultâneas, a leitura é atravessada por gargalos potenciais que entravam seu aprendizado. A partir de evidências de trabalhos sobre processamento de sentenças e processamento da leitura, apontamos que um dos problemas que podem impactar a compreensão leitora seja uma possível falha no mapeamento da estrutura de períodos presentes em gêneros textuais do universo letrado, que se distanciam muito da língua vernacular. O foco na microestrutura, portanto, poderia auxiliar a reduzir a carga cognitiva inerente, direcionando a atenção para processar esses períodos. Esse deve ser um dos fatores que compõem a habilidade a que Maia (2018b) se refere como "consciência leitora".

A palavra consciência aqui é fundamental. Entender o texto como um diálogo interacional implica também entender que a gramática funciona como um veículo para os sentidos que são construídos. O desenvolvimento de recursos metacognitivos para lidar com esse objeto pequeno e, portanto, mais manipulável, que é o período, tem grande potencial para estimular o pensamento científico nas escolas. Situar a língua do aluno como objeto de estudo nos permite partir do conhecido para o potencial desconhecido. Esse deslocamento ampliaria a vinculação e a identificação com textos que, a princípio, podem parecer encapsulados e intransponíveis, incentivando, assim, o componente volitivo da leitura. Além disso, entendemos que o olhar analítico para o conhecimento implícito sobre as variedades vernaculares deve ser desenvolvido explicitamente durante a escolarização.

Percebemos um movimento histórico de característica pendular nas abordagens linguísticas dentro das escolas. Antes, as aulas de língua materna se ocupavam em escrutinar a estrutura gramatical, descolada do texto e do seu contexto, em árduas tarefas que mais prezavam pela lista extensa de rótulos do que pela identificação e processamento das estruturas. Dessa forma, percebeuse uma lacuna, dado que o conhecimento não chegava aos elementos da macroestrutura textual, levando a leituras por vezes ingênuas. Os esforços em levar à escola estratégias que visam à construção de uma leitura descendente é fundamental para o desenvolvimento da habilidade leitora, pois orienta os leitores a construírem interpretações que derivam da interação dialógica com o texto e seu contexto. Apesar de ser uma estratégia positiva, se utilizada de forma isolada, pode se tornar apenas um caminho para terminar a tarefa rapidamente e acarretar interpretações equivocadas -porque nem todos os textos vão respeitar as expectativas de mundo. Ou seja, com a mudança de foco, ganhou-se por um lado, mas, por outro, perdeu-se um espaço de reflexão sobre a estrutura das sentenças que é igualmente importante. Não podemos abandonar o que se conquistou a partir dos esforços da linguística textual, mas é importante redescobrir um olhar adequado para a sintaxe. Dessa forma, cada área precisará levantar os elementos centrais que a escola deve privilegiar, de modo que tenhamos o mais importante de cada saber valorizado e trabalhado nas salas de aulas brasileiras.

A moral é simples: pensar que há apenas uma maneira de abordar os fatos leva tipicamente a uma visão parcial (ou distorcida) da realidade. Em geral, é mais produtivo considerar as coisas de ângulos diferentes. E isso não é fácil. Requer, entre 
Volume 15 - Número 2 - ago/dez de 2020

outras coisas, a vontade de cooperar com os outros (frequentemente, de posições opostas) para entender a natureza das coisas. (GALLEGO; CHOMSKY, 2020, p. 22) ${ }^{9}$

Nessa perspectiva, a prática de leitura deve atentar para o desenvolvimento da metacognição gramatical, a partir de uma reflexão consciente sobre a estrutura das sentenças, junto com os aspectos socioculturais e ideológicos, inerentes à construção dialógica de um texto. Nosso objetivo aqui não é impor à escola o estado da arte da psicolinguística, ou de qualquer outra especialidade acadêmica, mas promover um diálogo possível entre diversos saberes. Se a escola assumir o preciosismo de que nada de cada área pode se perder, de que tudo é extremamente relevante, ficará presa em um labirinto dos especialistas. O desafio das escolas é sempre enorme, mas é necessário que haja uma curadoria dos saberes das diferentes áreas e de seus elementos centrais que devem chegar aos alunos. Além de se estabelecer o equilíbrio entre os saberes especializados e escolares, é necessário, antes de tudo, compreender a leitura como uma prática volitiva. Portanto, qualquer atividade sobre a leitura precisa, em primeiro lugar, estimular o desejo de ler. Qualquer desequilíbrio entre esses elementos leva a uma concepção redutora da leitura. As especialidades da academia devem, portanto, ser consumidas com moderação. Traduzir o conteúdo acadêmico para a escola passa por essa sensibilidade: trazer novos ventos, mas com relevância, diálogo e pertencimento.

\section{Referências}

AMARAL, Luis. ROEPER, Tom. Multiple Grammars and second language representation. Second language research, vol. 30, no. 1, p. 3-36, 2014.

CASTLES, Anne; RASTLE,; NATION, Kathleen. Ending the reading wars: Reading acquisition from novice to expert. Psychological Science in the Public Interest, no. 19, p. 5-51, 2018. https://doi.org/10.1177/1529100618772271.

CHOMSKY, Noam. Knowledge of language: Its nature, origin, and use. [S. l.]: Greenwood Publishing Group, 1986.

CHRIST, T. WANG, X.C. Closing the Vocabulary Gap?: A Review of Research on Early Childhood Vocabulary Practices. vol. 35, no. 5, p. 426-458, 2011. https://doi.org/http://dx.doi.org/10.1080/02702711.2010.495638.

COSTA, A. L.; COSTA, A.; GONÇALVES, A. Consciência linguística: aspectos sintáticos. In: FREITAS, Maria João; SANTOS, Ana Lúcia (eds.). Aquisição de língua materna e não materna: questões gerais e dados do português. Textbooks in Language Sciences. Berlin: Language Science Press, 2017. vol. 3, p. 409-438.

CRAIN, Stephen LILLO-MARTIN, Diane. An introduction to linguistic theory and language acquisition. Oxford: Blackwell Publishers, 1999.

DE BEAUGRANDE, Robert. New foundations for a science of text and discourse: cognition,

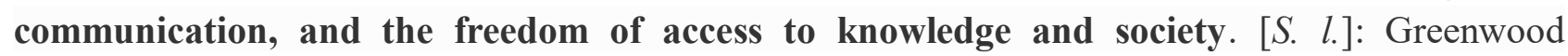
Publishing Group, 1997.

\footnotetext{
9 "The moral is simple: thinking that there is only one way to approach the facts typically leads to a partial (or distorted) view of reality. In general, it is more productive to consider things from different angles. And that is not easy. It requires, among other things, the will to cooperate with others (often, from opposite positions) to understand the nature of things."
} 
Volume 15 - Número 2 - ago/dez de 2020

DEHAENE, Stanislas.. Os neurônios da leitura: como a ciência explica a nossa capacidade de ler. trans. by Leonor Scliar Cabral. Porto Alegre: Penso, 2012.

DEHAENE, Stanislas. How we learn: Why Brains Learn Better than Any Machine... For Now, Penguin, 2020.

DING, NAI; MELLONI, LUCIA; ZHANG, HANG; TIAN, XING; POEPPEL, D. Cortical tracking of hierarchical linguistic structures in connected speech. Nature neuroscience, vol. 19, no. 1, p. 158164, 2016.

DYPEDAHL, M. A Metacognitive Approach to Intercultural Learning in Language Teacher Education. In: HAUKÅS, Å.; BJØRKE, C.; DYPEDAHL, M. (eds.). Metacognition in Language Learning and Teaching. New 2018. https://doi.org/https://doi.org/10.4324/9781351049146.

FLESCH, Rudolph. Why Johnny Can't Read - and What You Can Do About It. New York: Harper Collins, 1955.

FODOR, Jerry A; BEVER, Thomas G. The psychological reality of linguistic segments. Journal of verbal learning and verbal behavior, vol. 4, no. 5, p. 414-420, 1965.

FREIRE, Paulo. A Importância do Ato de Ler: em três artigos que se completam. São Paulo: Cortez, 2011. vol. 22, (Coleção Questões de Nossa Época).

GALLEGO, A.J., CHOMSKY, N. The Faculty of Language: a biological object, a window into the mind, and a bridge across disciplines. Revista de la Sociedad Espanola de Linguistica, 2020.

GEE, James, P. Situated Language and Learning: A critique of traditional schooling. [S. $l$.]: Routledge, 2004.

GLEITMAN, L. R. The structural sources of verb meanings. Language Acquisition, no. 1, p. 3-55, 1990.

GOUGH, P. B. One second of reading. In: KAVANAGH, J.F.; MATTINGLY, I.G. (eds.). Language by ear and by eye. [S. l.]: The MIT Press, 1972. p. 353-378.

HENAUT, A. C.; BASTOS, A.; PATRÍCIO, M.G. Estratégias de Leitura: um olhar psicolinguístico. Cadernos de Resumo do Centro de Letras e Artes, no. 8, 2017.

HOFF, E. How social contexts support and shape language development. Developmental Review, no. 26, p. 55-88, 2006.

HONDA, M.; O’NEIL, W. Triggering science formation capacity through linguistic inquiry. In: HALE, K.; KEYSER, S.J. (eds.). The view from building 20: essays in honor of Sylvian Bromberger. [S. l.: s. n.], 1993. p. 229-256.

HONDA, Maya; O’NEIL, Wayne. On thinking linguistically. Revista Linguíftica, vol. 13, no. 1, p. 52-67, 2017.

HYONA, J.; LORCH JR, R. F.; KAAKINEN, J. Individual differences in reading to summarize expository text: Evidence from eye fixation patterns. Journal of Educational Psychology, no. 94, p. 44-55, 2002.

ILARI, Rodolfo; BASSO, Renato Miguel. O "letramento linguístico" de Maya Honda e o contexto brasileiro: um breve percurso histórico. Revista Linguíftica, vol. 13, no. 1, p. 66-85, 2017.

KENEDY, Eduardo. O Status Da Norma Culta Na Língua-I dos Brasileiros E Seu Respectivo Tratamento Na Escola: Algumas Contribuições De Estudos Formalistas À Educação. In: SIMONE 
Volume 15 - Número 2 - ago/dez de 2020

GUESSER (ed.). LINGUÍSTICA: PESQUISA E ENSINO. Boa Vista: EDUFRR, 2016. vol. 2, p. $185-208$.

KENEDY, Eduardo. Possíveis contribuições da Linguística Gerativa a formação do professor de Língua Portuguesa. Revista de Letras, vol. 1, no. 32, 2013.

KHALIFA, H.; WEIR, C. Examining reading: Research and practice in assessing second language reading. Cambridge: Cambridge University Press, 2009.

KLEIMAN, A. Oficina de leitura: teoria \& prática. São Paulo: Pontes, 2013.KOCH, I. V.; ELIAS, V. M. Ler e Compreender os Sentidos do Texto. São Paulo: Contexto, 2007.

KOCH, Ingedore G. Villaça. Desvendando os segredos do texto. São Paulo: Cortez, 2018.

LABERGE, D.; SAMUELS, S. J. Toward a theory of automatic information processing in reading. Cognitive Psychology, vol. 6, no. 2, p. 293-323, 1974. https://doi.org/https://doi.org/10.1016/00100285(74)90015-2.

LUST, Barbara C. Child language: Acquisition and growth. Cambridge: Cambridge University Press, 2006.

MAIA, M; GARCIA, D. C.; FERNANDES, M. Metacognição e educação linguística. In: MAIA, M. (ed.). Psicolinguística e Metacognição na escola. Campinas: Mercado de Letras, 2019. p. 19-41.

MAIA, M.; FINGER, I. Processamento da Linguagem. Pelotas: EDUCAT, 2005.

MAIA, Marcus. Psicolinguística e educação. Campinas: Mercado de Letras, 2018.

MAIA, Marcus. Computação estrutural e de conjunto na leitura de períodos: um estudo de rastreamento ocular. In: MAIA, M. (ed.). Psicolinguística e Educação. Campinas: Mercado de Letras, $2018 \mathrm{~b}$.

MAIA, Marcus. Manual de linguística: subsídios para formação de professores indígenas na área de linguagem. Brasília: UNESC/MEC, 2006.

MARCUSCHI, Luiz Antônio. Exercícios de compreensão ou copiação. Em aberto, Brasília, vol. 16, no. 69, 1996.

MILLER, G. A. The magical number seven, plus or minus two: Some limits on our capacity for processing information. Psychological Review, vol. 62, no. 2, p. 81-97, 1956. https://doi.org/10.1037/h0043158.

MORGAN, J.; DEMUTH, K. Signal to syntax: Bootstrapping from speech to grammar in early acquisition. Mahwah: Lawrence Erlbaum Associates, 1996.

NASSAJI, Hossein. The role and importance of lower-level processes in second language reading. Language Teaching,

OLIVEIRA, R. P.; QUAREZEMIN, S. Gramáticas na Escola. Rio de Janeiro: Vozes, 2016.

PAYNE, Brennan; FEDERMEIER, Kara D. Individual Differences in Reading Speed are Linked to Variability in the Processing of Lexical and Contextual Information: Evidence from Single-trial Event-related Brain Potentials. WORD, vol. 65, no. 4, p. 252-272, 2019. DOI 10.1080/00437956.2019.1678826. Available at: https://doi.org/10.1080/00437956.2019.1678826.

PERFETTI, Charles A. Comprehending written language: A blueprint of the reader. In: BROWN, C.; HAGOORT, P. (eds.). The neurocognition of language. Oxford: Oxford University Press, 1999. p. 167-208.

PERFETTI, Charles A. Reading ability. New York: Oxford University Press, 1985. 
Volume 15 - Número 2 - ago/dez de 2020

PERFETTI, Charles A.; HART, L. The lexical quality hypothesis. In: VERHOEVEN, L.; ELBRO, C.; REITSMA, P. (eds.). Precursors of functional literacy. Amsterdam: John Benjamins Publishing Company, 2002. p. 189-213.

PERFETTI, Charles A.; LANDI, Nicole; OAKHILL, Jane. A aquisição da habilidade de compreensão da leitura. In: SNOWLING, M. J.; HULME, C. (ed.). A ciência da leitura. trans. by Ronaldo Cataldo Costa. Porto Alegre: Penso, 2103. p. 245-265.

PILATI, Eloisa. Linguística, gramática e aprendizagem ativa. 2nd ed. São Paulo: Pontes, 2017. PINKER, S. The Web, the Tree and the String. The Sense of Style: The Thinking Person's Guide to Writing in the 21st Century. New York: Penguin Books, 2014.

PINKER, S. Language Learnability and Language Development. Cambridge, MA, 1996.

RAYNER, K. \& POLLATSEK, A. The Psychology of Reading. Englewood Cliffs: Lawrence Erlbaum Associates, 1989.

REICHLE, E. D.; RAYNER, K.; POLLATSEK, A. The E-Z Reader model of eye movement control in reading: Comparisons to other models. Behavioral and Brain Sciences, no. 26, p. 445-476, 2003. RIBEIRO, S. O processamento da oração Principal Em Períodos Compostos Por Subordinação e Coordenação: Padrões de Leitura e Formação de Pontos de Vista. 2017. Universidade Federal do Rio de Janeiro, 2017.

ROEPER, Tom. Universal bilingualism. Bilingualism: language and cognition, vol. 2, no. 3, p. 169-186, 1999.

SAFFRAN, Jenny R.; ASLIN, Richard N.; NEWPORT, Elissa L. Statistical learning by 8-month-old infants. Science, vol. 274, no. 5294, p. 1926-1928, 1996.

SANTOS, Leonor W. dos. Textos literários e não literários: a formação do leitor crítico. 2007. Simpósio Nacional de leitura (SINALE) [...]. João Pessoa: UFPB, 2007. p. 527-532.

SMITH, F. Understanding Reading. New York: Holt, Rinehart and Winston, 1971.

SMITH, K.; MCMAHON, L. Understanding order information in sentences: some recent work at Bell Laboratories. In: D’ARCAIS, G.B. Flores; LEVELT, J. (eds.). Advances in Psycholinguistics. New York: Elsevier, 1970.

STANOVICH, K. E. Toward an interactive-compensatory model of individual differences in the development of reading fluency. Reading Research Quarterly, no. 16, p. 32-71, 1980.

STEINHAUER, Karsten; ALTER, Kai; FRIEDERICI, Angela D. Brain potentials indicate immediate use of prosodic cues in natural speech processing. Nature neuroscience, vol. 2, no. 2, p. 191-196, 1999.

STICHT, T. G.; JAMES, J. H. Listening and Reading. In: BARR, R.; KAMIL, M.; MOSENTHAL, P. (eds.). Handbook of Reading Research. New York: Longmans, 1984.

TELES, E. R.; LOPES, R. E. V. Linguística Formal como ensino de ciência na escola básica: uma experiência nas aulas de português. Revista da ABRALIN, vol. 17, no. 1, p. 110-150, 2019.

THALMANN, M.; SOUZA, A., S. OBERAUER, K. How does chunking help working memory? Journal of Experimental Psychology: Learning, Memory, and Cognition, no. 45, p. 37-55, 2019. THOMPSON, C.; SHAPIRO, L. Complexity in treatment of syn- tactic deficits. American Journal of Speech-Language Pathology, no. 18, p. 30-42, 2007. 